\title{
BMJ Open Sonic and ultrasonic oscillating devices for the management of pain and dental fear in children or adolescents that require caries removal: a systematic review
}

\author{
Stefano Cianetti, ${ }^{1}$ Iosief Abraha, ${ }^{2,3}$ Stefano Pagano, ${ }^{1}$ Eleonora Lupatelli, ${ }^{1}$ \\ Guido Lombardo ${ }^{1}$
}

To cite: Cianetti S, Abraha I, Pagano S, et al. Sonic and ultrasonic oscillating devices for the management of pain and dental fear in children or adolescents that require caries removal: a systematic review. BMJ Open 2018;8:e020840. doi:10.1136/ bmjopen-2017-020840

- Prepublication history and additional material for this paper are available online. To view these files, please visit the journal online (http://dx.doi. org/10.1136/bmjopen-2017020840).

Received 27 November 2017 Revised 8 March 2018 Accepted 20 March 2018

\section{Check for updates}

${ }^{1}$ Department of Surgical and Biomedical Sciences, Universita degli Studi di Perugia, Perugia, Italy

${ }^{2}$ Health Planning Service, Regional Health Authority of Umbria, Perugia, Italy

${ }^{3}$ Innovation and Development Department, Agenzia Nazionale per i Servizi Sanitari Regionali (Age.Na.S.), Rome, Italy

Correspondence to Dr losief Abraha; iosief_a@yahoo.it

\section{ABSTRACT}

Objectives To evaluate the effectiveness and degree of acceptance by children and adolescents of the use of oscillating tips compared with rotating drills.

Design Systematic review.

Data sources PubMed, the Cochrane Central Register of Controlled Trials (CENTRAL), the Cochrane Library and Web of Science (October 2017).

Eligibility criteria Controlled randomised or nonrandomised trials that evaluated sonic and ultrasonic oscillating devices versus rotating drill.

Data extraction Eligible studies were selected and data extracted independently by two reviewers. Risk of bias was assessed using the Cochrane Method.

Results Two controlled clinical trials comprising 123 children aged 2-12 years old were identified. Both trials were at high risk of selection bias and unclear risk of detection bias. In one trial, pain due to the use of oscillating drill resulted lower than employing rotating drill (Verbal Hochman Scale: RR 0.64 (95\% Cl 0.41 to 1.00); Visual Facial Expression Scale: RR 0.64 (95\% Cl 0.44 to 0.94$)$ ). In another study, compared with traditional drill ultrasonic tip was associated with a lower level of patient's discomfort (RR 0.40 (95\% Cl 0.20 to 0.79$)$ ) but not with dental anxiety (RR 1.29 (95\% Cl 0.97 to 1.71)). The effectiveness of the removal of caries as well as fillings durability were only considered in one study, but no statistically significant differences were found between the two interventions.

Conclusions The evidence based on two low-quality studies was insufficient to conclude that the use of oscillating tips for the management of pain and dental fear in children or adolescents compared with rotating drills was more effective.

\section{INTRODUCTION}

Sonic and ultrasonic devices are commonly used in dental practices such as, periodontology, ${ }^{1}$ oral surgery, ${ }^{2}$ endodontics ${ }^{3}$ and prosthetics. ${ }^{4}$ High-frequency ultrasonic devices have been used in conservative dentistry since the $1950 \mathrm{~s}^{5}$. Sonic and ultrasonic tips have been

\section{Strengths and limitations of this study}

- This paper addresses systematically the issue of sonic or ultrasonic oscillating devices for the management of pain and dental fear in children or adolescents.

- Cochrane Method-based risk of bias was used to assess the quality of the studies.

- The number of studies identified was limited.

- A narrative summary of the results is provided as data could not be pooled.

declared useful for precise and controlled removal of both caries and unsupported hard tissue free of caries. ${ }^{6}$ Sonic and ultrasonic instruments remove caries by abrading hard and soft dental tissues with oscillating diamond-coated tips. The ultrasonic tips carry out high-frequency linear oscillations, ranging from 6500 to $40000 \mathrm{~Hz}$, powered by piezo-driven inserts. Similarly, the sonic tips also execute low-frequency $(6000 \mathrm{~Hz})$ elliptic oscillations generated by an air scaler insert. Both oscillating abrasion systems are cooled with a water spray. ${ }^{5}$

These oscillating tips offer an innovative technique for the removal of caries as a result of several characteristics: (1) minimally invasive cavity preparation; (2) ample visibility of caries during cavity preparation; (3) easy removal of caries located in hard-to-reach areas (ie, lingual or buccal surfaces of posterior teeth) due to specific angulate shapes of oscillating tips; ${ }^{6}$ (4) low frequency of iatrogenic damage to neighbouring teeth when proximal caries are treated ${ }^{78} ;(5)$ low noise level and (6) low requirement of administration of anaesthesia during patient treatment. ${ }^{6}$

Despite the proven effectiveness of traditional low-speed and high-speed rotating 
instruments to remove caries and to prepare cavities for dental fillings, these instruments could be inappropriate when a certain strata of the population with evident dental anxiety (12\%-20\%), such as young children, are treated by dentists. ${ }^{9}$ In many cases, the use of traditional rotating burs to remove caries is combined with local administration of anaesthesia. Anaesthetic injection notoriously represents one of the most significant dental anxiety triggers, reducing compliance with dental treatment. ${ }^{10-16}$ Furthermore, sight of the traditional rotating drill, as well as the vibration and noise felt by patients during treatment, represents another important dental anxiety stimulus that could be avoided by new approaches and alternative devices used in the management of caries. ${ }^{10} 11141718$

Sonic and ultrasonic devices belong to an alternative group of the so-called 'micro-traumatic' tools to remove caries that include several other alternative devices/ approaches to rotating instruments. The most noteworthy are Atraumatic Restorative Techniques, ${ }^{19}$ chemochemical removal of caries,${ }^{20}$ lasers,${ }^{21}$ air abrasion and polymer rotary burs. ${ }^{22}$ Oscillating devices, therefore, are potentially useful tools to treat caries with a 'psychological microinvasive approach' reducing the recourse to more complicated pharmacological procedures, such as conscious sedation or general anaesthesia. It is well reported that psychological condition impacts the children's' and adolescents' oral health status, ${ }^{10} 132324$ by conditioning their dental service attendance as well as their compliance with treatment. ${ }^{1725-29}$ Hence, sonic and ultrasonic ablation devices can be attractive alternative tools to overcome concerns regarding dental anxiety.

The aim of the present investigation was to systematically review the current available literature comparing the use of sonic or ultrasonic devices with rotating drills for the management of pain and dental fear in children or adolescents who require caries removal.

\section{Review scientific question}

The primary research question was 'Are sonic and ultrasonic devices effective in the management of pain and dental fear in children and adolescents who require caries removal?' The population of interest was children or adolescents who required caries removal. The intervention of interest was any oscillating tip that was compared with standard drills, whereas the primary outcomes were pain and dental anxiety.

\section{METHODS}

\section{Criteria for considering studies for this review}

Types of studies

Randomised controlled trials (RCTs) and controlled clinical trials (CCTs) without language limitations.

\section{Types of participants}

Children and adolescents with caries. Studies carried out on patients affected by specific oral or systemic diseases were excluded. Both deciduous and permanent teeth were included, with only restored and non-vital teeth excluded.

\section{Types of interventions}

Studies that evaluated sonic and ultrasonic devices to remove caries and to prepare cavities for fillings compared with conventional high-speed and/or low-speed rotating instruments. No limitations were considered concerning restorative materials used for filling cavities.

\section{Types of outcome measures}

Primary outcomes: episodes of pain and discomfort during and after treatment, dental fear and removal of caries as confirmed by clinical, radiological or other validated assessment tools. ${ }^{30}$ Secondary outcomes: durability of restoration (marginal integrity), recurrent caries, pulpal phlogosis or necrosis, patients' acceptance of treatment, patients' preferences, need for anaesthesia, dental practitioner assessment, duration of treatment, costs of intervention and adverse events.

\section{Search methods to identify studies}

A systematic literature review was carried out in the most relevant electronic databases (October, 2017): Medline, the Cochrane Central Register of Controlled Trials (CENTRAL), the Cochrane Library and Web of Science.

Moreover, studies reported in reference lists of obtained articles (reviews and/or studies) and listed in the chapter of the most relevant textbooks in this field were screened in order to find additional relevant studies. If multiple publications of a single trial were available, only the first publication was considered, except in cases where additional data were reported, such as delayed outcome results. A search strategy in the above-mentioned electronic databases was carried out using a combination of keywords and Medical Subject Headings (MeSH) (online supplementary appendix 1).

\section{Selection of studies}

Two review authors independently assessed the titles and extracts of all records identified in the electronic databases (SC and EL). The full text of studies potentially fulfilling the inclusion criteria were requested. Disagreement between review authors, regarding any records meeting the inclusion criteria, was resolved by discussion. Where resolution was not possible, a third review author was consulted (SG).

\section{Data extraction and management}

Data from included studies were independently extracted by two review authors (SP and RG), and disagreements were resolved by means of discussion or involvement of a third review author (LP). A data extraction sheet (table) was used to collect data. The retrieved data were divided, based on their characteristics, into the following fields: (1) studies (year of publication, country); patients (number of participants, age and gender); intervention (type of oscillating device); comparator (placebo, high-speed or 
low-speed rotating instruments) and outcomes (primary and secondary). Any adverse events reported in the study were recorded. When full texts of studies potentially meeting the inclusion criteria were unavailable, the study authors were contacted by email whenever possible.

\section{Assessment of risk of bias in included studies}

Two review authors (IA and GL) independently evaluated the risk of bias of all included studies using the Cochrane Collaboration's risk of bias tool (Chapter 8 of the Cochrane Handbook ${ }^{31}$ ). Disagreements were resolved by discussion and if consensus could not be reached, a third review author (AM) was consulted. The following types of risk of bias were evaluated in each included RCT: random sequence generation (selection bias); allocation concealment (selection bias), blinding of participants and personnel (performance bias), blinding of outcome assessment (detection bias), ${ }^{32}$ incomplete outcome data (attrition bias) and ${ }^{33} 34$ selective reporting (reporting bias). ${ }^{35} 36$ The studies can be classified into (1) low risk of bias (plausible bias unlikely to seriously alter the results), (2) unclear (plausible bias that raises some doubt about the results) or (3) high risk of bias (plausible bias that seriously weakens confidence in the results).

\section{Measures of treatment effect and data synthesis}

Where possible, for dichotomous outcomes we calculated risk ratios (RR) with 95\% CI for each trial; for continuous data, we calculated mean difference. In the case of studies of split-mouth design, we planned to calculate $\log \mathrm{RR}$ and SE separately for each outcome.

We planned to combined data from split-mouth studies with data from parallel-group trials using the method suggested by Elbourne et al, ${ }^{37}$ employing the generic inverse variance method available in Review Manager V.5. Due to heterogeneity of the data, it was not possible to conduct any meta-analysis.

\section{Unit of analysis issues}

We planned to handle any unit of analysis issues in split-mouth trials according to the recommendations of Section 16.4 of the Cochrane Handbook for Systematic Reviews of Interventions. ${ }^{31}$

\section{Patient and public involvement}

Patients and the public were not directly involved. This was a retrospective study based on the consultation of the electronic medical literature.

\section{RESULTS}

\section{Results of the searches}

The electronic database search identified 373 records up to October 2017. From the entire set of selected records, 111 duplicates were removed and 262 records were screened. After a detailed evaluation of the titles and extracts from the electronic database and manually checking the reference lists of papers, 15 records were considered relevant for a further full-text examination. ${ }^{6} 38-49$ All 15 full texts were obtained and assessed for eligibility. The study screening process is described in figure 1. Thirteen studies, that had potentially met the inclusion criteria, were finally excluded due to their study designs. ${ }^{4} 638404244-4750-52$ Excluded studies with reasons for their exclusion are listed in the online supplementary appendix 2. Only two controlled clinical trials were identified and included in the review. ${ }^{41} 43$ Agreement of selection and quality appraisal procedures between the reviewers was almost perfect $(\kappa>0.94)$.

\section{Characteristics of included studies}

The two CCTs had a split-mouth design, involving a total of 123 child participants with ages ranging from 2 to 12 years. $^{41} 43$

The first study was carried out in China and it involved 72 children, aged 3-12, who visited the Peking University Department of Paediatric Dentistry. ${ }^{43}$ This split-mouth design trial compared oscillating ultrasonic tips with traditional rotating drills in pairs of unspecified analogous teeth situated on different sides of the same dental arc and affected by caries with similar characteristics. Overall 186 teeth were treated, 93 with ultrasonic tip (intervention group) and 93 with traditional rotating instruments (control group). Of the overall 186 treated dental elements, 156 were primary teeth while 30 were permanent teeth. In each patient, at least one pair of teeth was treated. In both groups, anaesthesia was not used. The following elements were evaluated in the study: episodes of pain during treatment; dental anxiety (measured in terms of the patient's cooperation in the dental chair) and treatment duration. The completeness of caries removal was also assessed at the end of each cavity preparation through visual evaluation and dental exploration (dental tissue texture and colour). The level of pain felt by the patients during treatment was recorded with a self-reported visual Five Face Rating Scale, varying from 0 (absence of pain) to 4 (severe pain). The level of both anxiety and collaboration shown by paediatric patients in the dental chair was assessed using a modified three-level Venham Rating Scales for anxiety and uncooperative behaviour ranging from 0 (for full cooperation without patient anxiety) to 2 (for a completely uncooperative and highly anxious patient). During three follow-up visits conducted after 1 week, at 3 months and at 6 months, the level of sensitivity felt by patients on the restored molars (integrity and duration) was also evaluated (table 1).

The second trial was conducted in Poland and included 31 children, aged 7-11, who visited the Department of Paediatric Dentistry of Cracow University, with at least two occlusal decayed permanent molars, one on each side of the two upper and lower dental arcs (split-mouth design). ${ }^{41}$ Chomyszyn-Gajewska and colleagues evaluated an ultrasonic powered tip, in combination with a micro-abrasive suspension (silicon-carbide, grain-size 40-50 vm), compared with a traditional drill. In this trial, 31 right-side molars were treated with a traditional high speed drill and the same number of left-side molars were treated with ultrasonic-powered tips. Overall, 62 

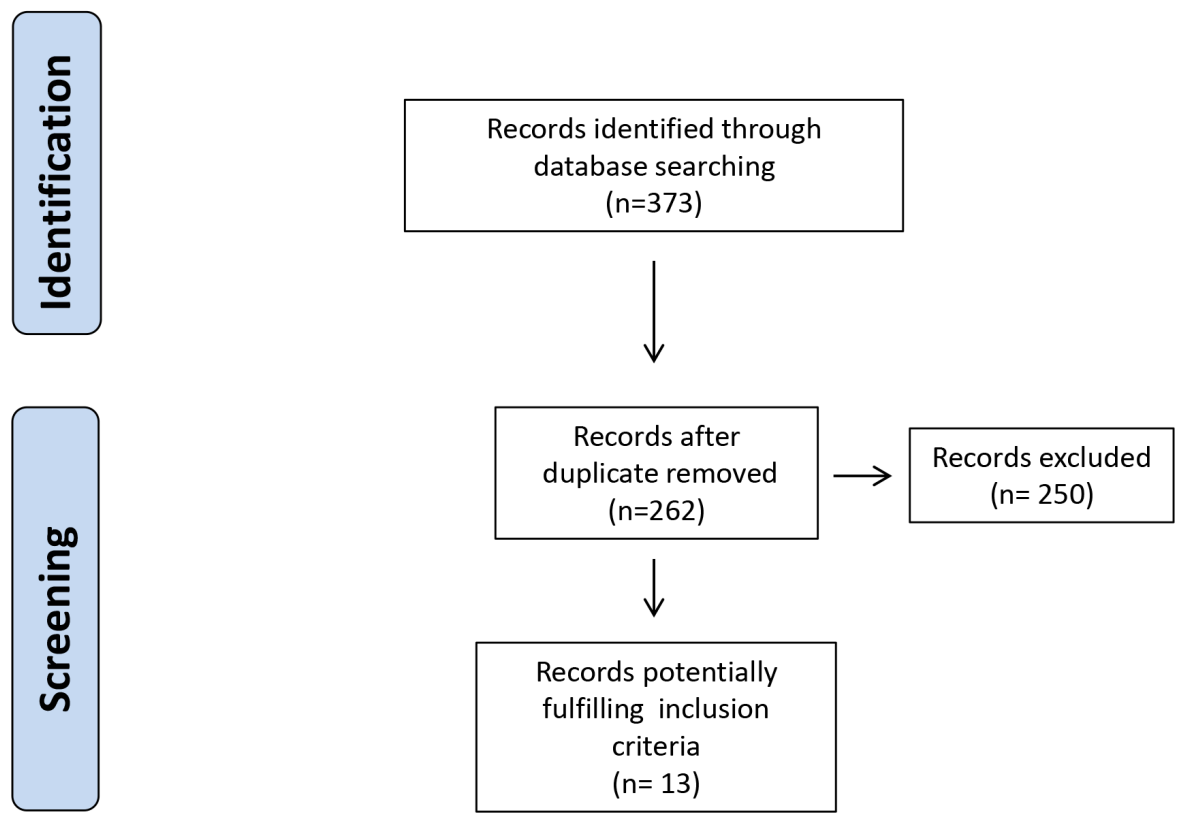

Records potentially

fulfilling inclusion

criteria

$(n=13)$

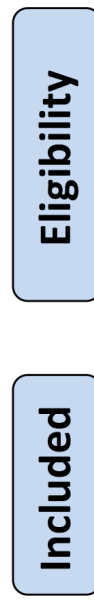

$\downarrow$

Other full-texts
identified through
other sources
$(n=2)$

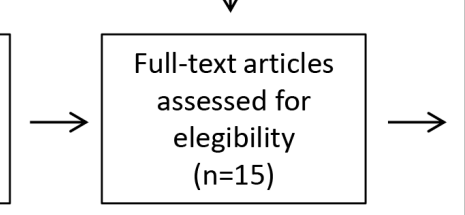

Full-text articlesexcluded with reason $(n=13)$

Descriptive study $(n=4)$

Case report $(n=3)$ Narrative review $(n=2)$ Observational study $(n=1)$ In vitro study $(\mathrm{n}=3)$

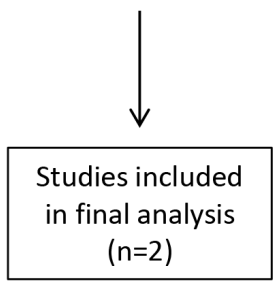

Figure 1 Literature search flow chart.

occlusal caries were treated without anaesthesia. In both the intervention and control groups, teeth were matched concerning caries depth (DIAGNOdent, KavoDental) and type of treated tooth (maxillary or mandibular molars). The patients with a high level of dental anxiety (determined with the self-reported Cora Dental Anxiety Scale before beginning treatment) and patients with a history of uncooperative behaviour or disability were excluded from the study. The evaluated outcomes included episodes of pain during treatment and the duration of treatment. The level of pain experienced by each patient during treatment was recorded using the following two self-reported scales: (1) the Hochman Scale (a verbal scale) or (2) a Facial Expression Scale (a visual five face scale). Both scales rated the pain experienced in five levels ranging from no pain (level 0) to severe pain (level 5). The procedures and diagnostic tools used to assess the complete removal of caries at the end of each cavity preparation were not described (table 1).

\section{Quality assessment of the body of evidence}

By default, the two included trials were not randomised and were considered at high risk of selection bias. In addition, none of the studies reported whether the outcome assessor was blinded and were judged unclear in terms of detection bias. No concern was identified in terms of attrition bias as well as selective reporting bias. Basic characteristics of the patient population were similar between the groups. Figure 2 describes the risk of bias of the two trials.

\section{Effects of interventions}

\section{Dental caries removal}

This outcome was reported only by $\mathrm{Li}$ and co-authors. ${ }^{43}$ In this studies, no cases of residual caries were described in either intervention group. Analysis did not show any 


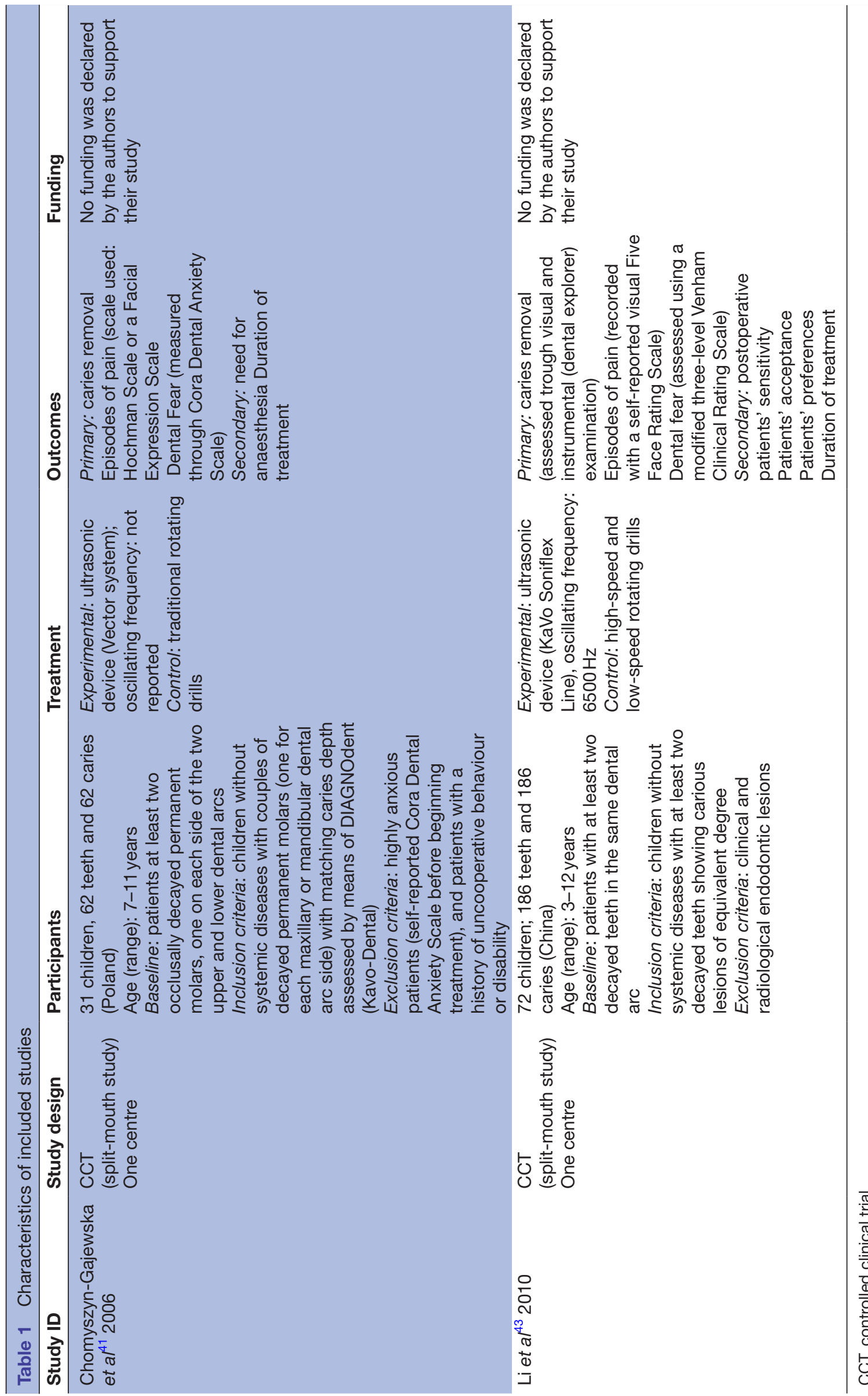




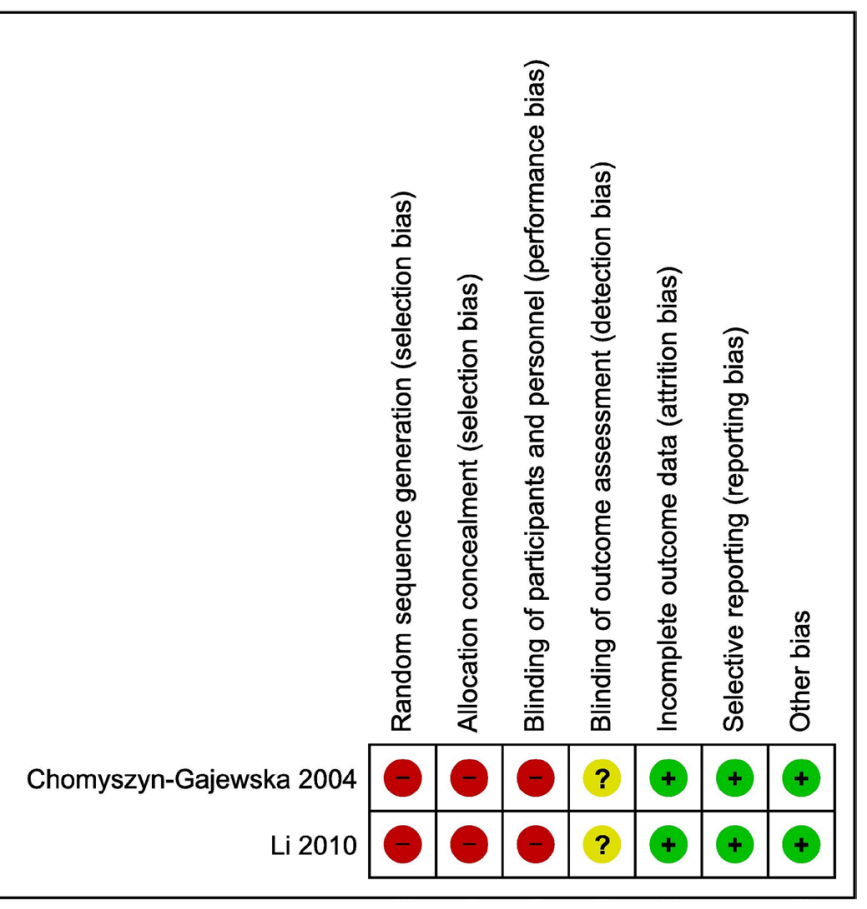

Figure 2 Risk of bias summary: review authors' judgements about each risk of bias item for each included study.

difference between the sonic and standard drill (one study, 93 treated caries in each group, RR 1.00 (95\% CI 0.98 to 1.02$)$ ).

\section{Dental anxiety}

This outcome was reported only by $\mathrm{Li}$ and co-authors. ${ }^{43}$ In this study, the dental anxiety was measured together with patient cooperation forming the following single outcome: dental anxiety and patient's cooperation. The percentage of children showing dental anxiety and negative cooperation with the dentist was lower when an ultrasonic tip $(n=39 / 93 ; 42 \%)$ was used than when a traditional drill was used $(n=51 / 93 ; 55 \%)$ but the difference was not statistically significant (RR 0.78 (95\% CI 0.58 to 1.03$)$ ).

\section{Pain}

This outcome was considered only by Chomyszyn-Gajewska and co-authors' trial. ${ }^{41}$ When the Verbal Hochman Scale was employed, 14 out of 31 participants (45\%) treated with an ultrasonic tip and abrasive suspension reported pain compared with 22 participants $(71 \%)$ treated with a traditional drill (RR 0.64 (95\% CI 0.41 to 1.00$) ; \mathrm{p}=0.05)$. Similarly, when the Visual Facial Expression Scale was used, 16 paediatric patients $(50 \%)$ treated with a traditional drill reported pain or discomfort compared with 25 patients $(22 \%)$ treated with an ultrasonic tip and abrasive suspension (RR 0.64 (95\% CI 0.44 to 0.94 ); $\mathrm{p}=0.02$ ).

\section{Discomfort}

Only $\mathrm{Li}$ and co-authors reported on this outcome. ${ }^{43}$ Patient discomfort during dental treatment was usually due to sight, noise or vibration related to use of ablating instruments. In the intervention group (ultrasonic tip), children experienced moderate or high uncomfortable sensation (for values within the latest two levels of the Five Faces Rating Scale) in 10 out of overall 93 (11\%) during treatment. Conversely, in the control group (traditional rotating drill) children felt a comfortable or slightly uncomfortable experience only in 25 out of 93 $(27 \%)$ of the cases. A statistically significantly difference was found between these two compared instruments in terms of discomfort, with a better performance in favour of an ultrasonic tip (RR 0.40 (95\% CI 0.20 to 0.79 ); $\mathrm{p}=0.008))$.

\section{Patients' preference}

Of the two included studies, only $\mathrm{Li}$ and co-authors ${ }^{43}$ demonstrated an overwhelmingly higher percentage of paediatric patients $(88.2 \%)$ who preferred to be treated with ultrasonic devices for future dental care. Conversely, only a lower percentage of study participants (11.8\%) chose the traditional rotating drill. In the other study, no data on this outcome were reported.

\section{Duration of treatment}

In Li and co-authors' study, the traditional drill was statistically significantly faster at ablation compared with the ultrasonic tip (average time: $3.5 \mathrm{SD} 2.3 \mathrm{~min}$ with vs $4 \mathrm{SD}$ 2.5 min; $\mathrm{p}<0.05$ ). Likewise, Chomyszyn-Gajewska and co-authors demonstrated that in terms of length of time to prepare cavities, rotating drills were significantly faster (3.9 during treatment for dentinal caries just beyond the amelo-dentinal junction; $5.5 \mathrm{~min}$ during treatment for dentinal caries advancing for at least half the depth of the dentine) compared with ultrasonic tips (9 to $16.8 \mathrm{~min}$ ) $(\mathrm{p}<0.0002)$.

\section{Durability of restoration}

Of the two studies, only Li and co-authors considered the durability of restoration. ${ }^{43}$ They found that all 93 dental fillings in both intervention and control groups resulted kept inside their cavities at 1 week, 3 months or 6 months. Moreover, in this study also, the dental sensibility was considered such sign of filling integrity over time. One out of 93 filled teeth in the intervention group versus 4 out of 93 restored teeth in the control group resulted with a certain degree of sensibility at 6 months after treatment control visit

\section{Other outcomes}

None of the studies evaluated the following outcomes: recurrent caries, need for anaesthesia, pulpal phlogosis or necrosis, dental practitioner opinion, costs of intervention and adverse events.

\section{DISCUSSION}

\section{Summary of findings}

The use of oscillating devices for caries removal is becoming more common among dental practitioners. ${ }^{45}$ Unfortunately, the high expectations regarding the use of oscillating devices to remove caries were not completely supported by data from published clinical studies. Only a 
few methodologically low-quality clinical studies described the effectiveness of oscillating devices to manage caries. Therefore, the potential positive features of oscillating tips, in terms of caries removal and ultraconservative preparation of cavities, in addition to low pain, decreased discomfort and reduced anxiety induction, remain clinically unproven.

\section{Strength and limitation}

To provide a comprehensive synthesis of the evidence about oscillating devices for the management of dental fear, we systematically searched studies available in four electronic databases and search references of relevant studies. In addition, we used and assessed the methodological quality of the trial using the risk of bias method of the Cochrane Collaboration. Another strength of the present review was the adoption of a systematic and transparent method, and the use of duplicate, independent approach of the reviewers for study selection, data abstraction and data interpretation.

We acknowledge several limitation of our study. Despite a systematic literature review, only two Controlled Clinical Trials were found, both of which were considered to have unclear or high risk of selection, detection and attrition biases. ${ }^{41}{ }^{43} \mathrm{In}$ addition, in one trial, $\mathrm{Li}$ and co-authors rated both the cooperation level and anxiety shown by children in the dental chair by using a modified version of a rating scale named Venham Rating Scales for anxiety and uncooperative behaviour. Usually, all rating scales (based on a dentist assessment) are considered a valid tool to perform a child's behaviour cooperation assessment rather than an anxiety evaluation. ${ }^{53}$ The above-mentioned Venham Rating Scale represents an exception to this rule. This scale, indeed, is composed of two subscales: an Anxiety Rating Scale to measure dental fear and a Behaviour Rating Scale to evaluate the child's cooperation. The reliability and validity of this scale has been directly demonstrated by Venham some years after its realisation. ${ }^{54}$ However, in the $\mathrm{Li}$ and co-authors' study, as well-outlined before, a modified version of Venham Rating Scales for anxiety and uncooperative behaviour (composed of only one scale) was used and no validation studies about that were found. Consequently, unresolved concerns remain about the validity of anxiety and cooperation values measured in the $\mathrm{Li}$ and co-authors' study.

In the second trial, Chomyszyn-Gajewska and co-authors ${ }^{41}$ excluded from their study sample dental anxious and/or uncooperative children, whereas those represent the target population of greatest interest for the present review. This particular group of patients, indeed, is the one most advantaged by anxiety management procedures. Therefore, data derived from only non-anxious and dental care compliant patients (for whom ordinarily no anxiety management is required) generate doubts on their value in terms of applicability (indirectness) ${ }^{55}$ and relevance to improve the clinical practice. However, when children are considered during treatment of dental caries, they should be always deemed as at risk of developing dental fear particularly when they are younger. ${ }^{956}$ Unpleasant experiences, particularly when pain was felt during the earliest dental visits, represent an extremely relevant risk factor for children to develop dental anxiety ${ }^{25} 57-59$ that should be carefully avoided with an adequate dentist-child relationship.

Moreover, both trials presented a split-mouth design that might be considered a particular type of crossover study. In both study designs, the same patient is treated at two different times (one decayed tooth on each side of the mouth, one at a time) with alternating intervention and control devices for caries removal. The crossover study presents two relevant advantages over the most commonly adopted parallel study design: (1) the need of a lower sample size to obtain the same level of precision and statistical power, (2) a more accurate comparison between two different interventions due to the fact that single patient variations are lower than between different patients. However, crossover design could present a risk of a 'carryover effect' biassing the results. This effect is that the emotional impact of the patient's first dental visit lingering in his or her memory might affect perception of a second intervention and influence his or her pain perception $^{60}$

\section{Conclusions}

The lack of available literature with a high methodological quality prevented us from answering the main question of this systematic review. The effectiveness of sonic and ultrasonic tips for managing pain and dental fear in children and adolescents who required caries removal remains, therefore, unproven and further research is required.

Contributors SC, SP, EL and GL: conceived the original idea. IA and GL: designed the study; designed the search strategies. SC and GL: performed the search and screened titled and abstracts independently; drafted the manuscript. SP and GL: performed data abstraction. IA and EL: performed assessment of quality. IA, SP and EL: revised critically the manuscript. All the authors approved the final version of the manuscript.

Funding This study was funded by the National Centre for Disease Prevention and Control - Ministry of Health (Grant CCM 2015). The sponsor was not involved in the format of the study, the collection, the analysis or interpretation of the data, nor in the writing of the article and the decision to submit it for publication. The authors were independent from the study sponsors.

Competing interests None declared.

Patient consent Not required.

Provenance and peer review Not commissioned; externally peer reviewed. Data sharing statement No additional data are available.

Open Access This is an Open Access article distributed in accordance with the Creative Commons Attribution Non Commercial (CC BY-NC 4.0) license, which permits others to distribute, remix, adapt, build upon this work non-commercially, and license their derivative works on different terms, provided the original work is properly cited and the use is non-commercial. See: http://creativecommons.org/ licenses/by-nc/4.0/

(C) Article author(s) (or their employer(s) unless otherwise stated in the text of the article) 2018. All rights reserved. No commercial use is permitted unless otherwise expressly granted.

\section{REFERENCES}

1. Apatzidou DA. Modern approaches to non-surgical biofilm management. Front Oral Biol 2012;15:99-116. 
2. Carini F, Saggese V, Porcaro G, et al. Piezolelectric surgery in dentistry: a review. Minerva Stomatol 2014;63:7-34.

3. Abella F, de Ribot J, Doria G, et al. Applications of piezoelectric surgery in endodontic surgery: a literature review. J Endod 2014;40:325-32.

4. Koczarski MJ, Mitchell AL. Direct inlay restorations: utilization of sonic preparation technology in conjunction with ceramic inserts. Pract Proced Aesthet Dent 2007;19:555-60.

5. Mm J, Nk B, A P. Minimal intervention dentistry - a new frontier in clinical dentistry. J Clin Diagn Res 2014;8:ZE04-8.

6. Sheets CG, Paquette JM. Ultrasonic tips for conservative restorative dentistry. Dent Today 2002;21:102-4.

7. Lussi A. Damage to neighboring teeth during the preparation of proximal cavities. An in-vivo study. Schweiz Monatsschr Zahnmed 1995;105:1259-64.

8. Moopnar M, Faulkner KD. Accidental damage to teeth adjacent to crown-prepared abutment teeth. Aust Dent J 1991;36:136-40.

9. Cianetti S, Lombardo G, Lupatelli E, et al. Dental fear/anxiety among children and adolescents. A systematic review. Eur J Paediatr Dent 2017:18:121-30.

10. Olak J, Saag M, Honkala S, et al. Children's dental fear in relation to dental health and parental dental fear. Stomatologija 2013;15:26-31.

11. Ajayi DM, Arigbede AO. Barriers to oral health care utilization in Ibadan, South West Nigeria. Afr Health Sci 2012;12:507-13.

12. Alsarheed M. Children's perception of their dentists. Eur J Dent 2011;5:186-90.

13. Akbay Oba A, Dülgergil CT, Sönmez IS. Prevalence of dental anxiety in 7- to 11-year-old children and its relationship to dental caries. Med Princ Pract 2009;18:453-7.

14. Nakai $Y$, Hirakawa T, Milgrom P, et al. The children's fear survey schedule-dental subscale in Japan. Community Dent Oral Epidemiol 2005;33:196-204.

15. Majstorovic M, Veerkamp JS. Relationship between needle phobia and dental anxiety. J Dent Child 2004;71:201-5.

16. Kușcu OO, Akyuz S. Children's preferences concerning the physical appearance of dental injectors. J Dent Child 2006;73:116-21.

17. Muppa R, Bhupatiraju P, Duddu M, et al. Comparison of anxiety levels associated with noise in the dental clinic among children of age group 6-15 years. Noise Health 2013;15:190-3.

18. Chhabra N, Chhabra A, Walia G. Prevalence of dental anxiety and fear among five to ten year old children: a behaviour based cross sectional study. Minerva Stomatol 2012;61:83-9.

19. Kumar KV, Prasad MG, Sandeep RV, et al. Chemomechanical caries removal method versus mechanical caries removal methods in clinical and community-based setting: a comparative in vivo study. Eur J Dent 2016;10:386-91.

20. Olegário IC, Hesse D, Bönecker M, et al. Effectiveness of conventional treatment using bulk-fill composite resin versus atraumatic restorative treatments in primary and permanent dentition: a pragmatic randomized clinical trial. BMC Oral Health 2016;17:34.

21. Montedori A, Abraha I, Orso M, et al. Lasers for caries removal in deciduous and permanent teeth. Cochrane Database Syst Rev 2016;9:CD010229.

22. Ricketts DN, Pitts NB. Novel operative treatment options. Monogr Oral Sci 2009;21:174-87.

23. Kruger E, Thomson WM, Poulton R, et al. Dental caries and changes in dental anxiety in late adolescence. Community Dent Oral Epidemiol 1998;26:355-9.

24. Alvesalo I, Murtomaa $\mathrm{H}$, Milgrom $\mathrm{P}$, et al. The dental fear survey schedule: a study with finnish children. Int $J$ Paediatr Dent 1993;3:193-8.

25. Bezabih S, Fantaye W, Tesfaye M. Dental anxiety: prevalence and associated factors, among children who visited Jimma University Specialized Hospital Dental Clinic. Ethiop Med J 2013;51:115-21.

26. Colares V, Franca C, Ferreira A, et al. Dental anxiety and dental pain in 5- to 12-year-old children in Recife, Brazil. Eur Arch Paediatr Dent 2013;14:15-19.

27. Gustafsson A, Broberg A, Bodin L, et al. Dental behaviour management problems: the role of child personal characteristics. Int $J$ Paediatr Dent 2010;20:242-53.

28. Fayans E. Pediatric oral premedication: changes in the patterns of administration and safety. Compendium 1989;10:568.

29. Cinar AB, Murtomaa H. A comparison of psychosocial factors related to dental anxiety among Turkish and Finnish pre-adolescents. Oral Health Prev Dent 2007;5:173-9.

30. Bader JD, Shugars DA, Bonito AJ. Systematic reviews of selected dental caries diagnostic and management methods. J Dent Educ 2001;65:960-8.

31. Higgins JP, Altman DG, Gøtzsche PC, et al. The cochrane collaboration's tool for assessing risk of bias in randomised trials. BMJ 2011;343:d5928.
32. Savović J, Jones H, Altman D, et al. Influence of reported study design characteristics on intervention effect estimates from randomised controlled trials: combined analysis of metaepidemiological studies. Health Technol Assess 2012;16:1-82.

33. Abraha I, Cherubini A, Cozzolino F, et al. Deviation from intention to treat analysis in randomised trials and treatment effect estimates: meta-epidemiological study. BMJ 2015;350:h2445.

34. Abraha I, Cozzolino F, Orso M, et al. A systematic review found that deviations from intention-to-treat are common in randomized trials and systematic reviews. J Clin Epidemiol 2017;84:37-46.

35. Chan AW, Hróbjartsson A, Haahr MT, et al. Empirical evidence for selective reporting of outcomes in randomized trials: comparison of protocols to published articles. JAMA 2004;291:2457-65.

36. Macura A, Abraha I, Kirkham J, et al. Selective outcome reporting: telling and detecting true lies. The state of the science. Intern Emerg Med 2010;5:151-5.

37. Elbourne DR, Altman DG, Higgins JPT, et al. Meta-analyses involving cross-over trials: methodological issues. Int J Epidemiol 2002;31:140-9.

38. Tassery H, Levallois B, Terrer E, et al. Use of new minimum intervention dentistry technologies in caries management. Aust Dent J 2013;58 (Suppl 1):40-59.

39. Mota SP, Soares DN, Maia LC, et al. Effect of minimally invasive restorations on microorganism count in the oral cavity of a patient with early childhood caries. Eur Arch Paediatr Dent 2013;14:121-7.

40. Thomas MS, Kundabala M. Pulp hyperthermia during tooth preparation: the effect of rotary--instruments, lasers, ultrasonic devices, and airborne particle abrasion. J Calif Dent Assoc 2012;40:720-31.

41. Chomyszyn-Gajewska M, Kwapinska H, Zarzecka J. Pain perception in children during caries removal with the Vector ${ }^{\circledR}$ system: a pilot study. Eur J Paediatr Dent 2006;1:38-41.

42. Haase SL. An innovative approach to Class II preparation and restoration. Signature 1998;5:16-19.

43. Li J, Ge LH, Zhao SY. Evaluation of the use of ultrasonic hand piece and micro-invasive tips in children's dental caries therapy. Beijing Da Xue Xue Bao Yi Xue Ban 2010;42:752-5.

44. Koubi S, Tassery H. Minimally invasive dentistry using sonic and ultra-sonic devices in ultraconservative class 2 restorations. $J$ Contemp Dent Pract 2008;9:155-65.

45. Predebon JC, Flório FM, Basting RT. Use of CVDentUS diamond tips for ultrasound in cavity preparation. J Contemp Dent Pract 2006;7:50-8.

46. Wicht MJ, Haak R, Fritz UB, et al. Primary preparation of class II cavities with oscillating systems. Am J Dent 2002;15:21-5.

47. Banerjee A, Watson T, Banerjee DA. Dentine caries excavation: a review of current clinical techniques. Br Dent J 2000;188:476-82.

48. Hugo B. Oscillating procedures in the preparation technic (II). Their development and application possibilities. Schweiz Monatsschr Zahnmed 1999;109:269-85.

49. Krejci I, Dietschi D, Lutz FU. Principles of proximal cavity preparation and finishing with ultrasonic diamond tips. Pract Periodontics Aesthet Dent 1998;10:295-8.

50. Yildirim M, Seymen F, Keklikoglu N. The evaluation of the vector system in removal of carious tissue. Int J Dent 2010;2010:1-6.

51. Josgrilberg EB, Guimarães MS, Pansani CA, et al. Influence of the power level of an ultra-sonic system on dental cavity preparation. Braz Oral Res 2007;21:362-7.

52. Ntovas P, Doukoudakis S, Tzoutzas J, et al. Evidence provided for the use of oscillating instruments in restorative dentistry: A systematic review. Eur J Dent 2017;11:268-73.

53. Klingberg G, Broberg AG. Dental fear/anxiety and dental behaviour management problems in children and adolescents: a review of prevalence and concomitant psychological factors. Int J Paediatr Dent 2007;17:391-406.

54. Venham LL, Gaulin-Kremer E, Munster E, et al. Interval rating scales for children's dental anxiety and uncooperative behavior. Pediatr Dent 1980;2:195-202.

55. Guyatt GH, Oxman AD, Kunz R, et al. GRADE guidelines: 8 . Rating the quality of evidence--indirectness. J Clin Epidemiol 2011;64:1303-10.

56. Jeddy N, Nithya S, Radhika T, et al. Dental anxiety and influencing factors: a cross-sectional questionnaire-based survey. Indian J Dent Res 2018;29:10-15.

57. Skaret E, Raadal M, Berg E, et al. Dental anxiety among 18-yrolds in Norway, Prevalence and related factors. Eur J Oral Sci 1998;106:835-43.

58. Bergius M, Berggren U, Bogdanov O, et al. Dental anxiety among adolescents in St. Petersburg, Russia. Eur J Oral Sci 1997;105:117-22. 
59. de Carvalho RW, de Carvalho Bezerra Falcão PG, de Luna Campos GJ, et al. Prevalence and predictive factors of dental anxiety in Brazilian adolescents. J Dent Child 2013;80:41-6.
60. Kuscu OO, Akyuz S. Is it the injection device or the anxiety experienced that causes pain during dental local anaesthesia? Int $\mathrm{J}$ Paediatr Dent 2008;18:139-45. 